\title{
Statistical Analysis of Corrosion Inhibition of Water Hyacinth on Mild Steel in an Acidic Medium
}

\author{
Omoruwou $\mathrm{F}^{1}$, Okewale $\mathrm{AO}^{1^{\star}}$ and Owabor $\mathrm{CN}^{2}$ \\ ${ }^{1}$ Department of Chemical Engineering, Federal University of Petroleum Resources, Effurun, Nigeria \\ ${ }^{2}$ Department of Chemical Engineering, University of Benin, Benin City, Nigeria
}

\begin{abstract}
This present work investigated surface response modeling and optimization of corrosion inhibition of water hyacinth on mild steel surface in an acidic medium. This was achieved using the central composite design (CCD) experimental design. Response Surface Methodology was used to assess the effects of experimental process variables that influenced rate of corrosion, and for searching of optimum combinations of factors. The rate of corrosion on mild steel surface was study using weight loss method. The optimum process variables obtained from the quadratic model developed were $1.50 \mathrm{~g} / \mathrm{l}$ inhibitor's concentration, 8 hours exposure time, and temperature of $60^{\circ} \mathrm{C}$ with a predicted inhibitor's efficiency value of $82.89 \%$. The experimental result obtained from optimum value validation was $81.5 \%$ and the predicted optimum value was adequately represented. The mild steel corrosion inhibition was achieved through the double bond adsorption of carbonyl group existing in the inhibitor phytochemical constituent.
\end{abstract}

Keywords: Weight loss; Rate of corrosion; FTIR; Phytochemical test; Central composite design; Optimization

\section{Introduction}

Corrosion has been described as an irreversible interfacial reaction of a material with its environment destroying useful properties of the material (such as the ductility, electric conductivity and the malleability) by chemical or electrochemical processes with resultant losses including parts replacement, maintenance, repairs, painting, service interruption and loss of product through leakages and contamination [1]. The different techniques used in preventing corrosion, are lubrication, painting, cathodic and anodic protection, electro-painting, material selection, and the use of inhibitors [2]. The use of inhibitors has been widely accepted due to their ability to reduce the rate of corrosion when introduced into a corrosive environment [3]. While literature reports abound in the use of organic and inorganic substances to inhibit corrosion in metals [3-5], there are however, many inorganic corrosion inhibitors with secondary effects in damaging the environment due to their toxicity [3]. Over the years concerted efforts have been made towards replacing these inhibitors with green alternatives which are cheap, eco-friendly, non-toxic, and biodegradable. Researches carried out using plant extracts ranging from papaya leaves, garlic extract, aleos extract to hirta extract to determine their efficiency as corrosion inhibitors on metals and alloys of metals have shown that these plant extracts are efficient corrosion inhibitor on metals in different media $[3,6-9]$.

In recent times, water hyacinth (Eichhorniacrassipesis), a water weed and free floating plant that can grow to a height of 3 feet and has persistently constituted a major problem to water ways and aquatic life has been studied as a corrosion inhibitor by researchers and has been found effective in different environments such as acidic environment [10], neutral environment [11], chloride environment [12] and alkaline environment but the use of design of experiment to study the inhibitory action of water hyacinth on mild steel surface to determine the statistical effects of the inhibitory variables on corrosion study have not been used to our best knowledge which necessitated this work. This study therefore seeks to advance the use of Response Surface Methodology (RSM) as a good example of statistical - based approach is a comprehensive experimental design and mathematical modeling, through the partial regression fitting of the experimental factors [13]. RSM is a collection of mathematical and statistical techniques that are useful for modeling and analysis of engineering problems in which a response of interest is influenced by several variables [14]. It is a technique for designing experiments, building numerical models, evaluating the effects of variables, and searching for optimum combinations of factors [15]. This method is more practical compared to the conventional 'one variable at a time' approach as it arises from experimental methodology which includes interactive effects among the variables and, eventually it depicts, the overall effects of the parameters on the process [16].

\section{Materials and Methods}

\section{Materials}

The water hyacinth was collected from Agbahro community located in Effurun, Delta State, Nigeria. Soxhlet extractor apparatus, HANNA model $\mathrm{pH}$ - 211 ( $\mathrm{pH}$ meter), Genlab oven model Mino/75/f (oven), weighing balance of model (BH - 600), and beakers, were employed for this corrosion study. Hydrochloric acid, acetic acid, acetone, and ethanol solutions used were of analytical grades and were gotten from a qualified chemical dealer in Effurun, Delta State, Nigeria. Distilled water was procured from the Department of Chemistry Laboratory, Federal University of Petroleum Resources, Effurun Delta, State, Nigeria for sample preparation and solutions.

\section{Methods}

Pre-treatment of sample and sample characterization: The water hyacinth was shredded and dried in the oven at $60^{\circ} \mathrm{C}$ for a period of 48 hours. The water hyacinth particle size range of $600 \mu \mathrm{m}$ was used for the corrosion study.

*Corresponding author: Okewale AO, Department of Chemical Engineering Federal University of Petroleum Resources, Effurun, Nigeria, Tel: +2347032051208; E-mail: okewale.akindele@fupre.edu.ng

Received May 30, 2017; Accepted June 13, 2017; Published June 20, 2017

Citation: Omoruwou F, Okewale AO, Owabor CN (2017) Statistical Analysis of Corrosion Inhibition of Water Hyacinth on Mild Steel in an Acidic Medium. J Environ Anal Toxicol 7: 481. doi: 10.4172/2161-0525.1000481

Copyright: ( 2017 Omoruwou F, et al. This is an open-access article distributed under the terms of the Creative Commons Attribution License, which permits unrestricted use, distribution, and reproduction in any medium, provided the original author and source are credited. 
Citation: Omoruwou F, Okewale AO, Owabor CN (2017) Statistical Analysis of Corrosion Inhibition of Water Hyacinth on Mild Steel in an Acidic Medium. J Environ Anal Toxicol 7: 481. doi: 10.4172/2161-0525.1000481

Page 2 of 5

Fourier Transform Infrared Spectroscopy (FTIR): Water hyacinth of $600 \mu \mathrm{m}$ particle size was observed with FTIR spectroscopy (Buck Scientific model 530) with the range $500-4000 \mathrm{~cm}^{-1}$ (wavelength). The background material used in the analysis is potassium bromate $(\mathrm{KBr})$.

Analysis of the phytochemical constituents in water hyacinth leaf: Screening of phytochemical constituents of water hyacinth leaf extract was carried out to identify the active constituents in the extract. The qualitative and quantitative methods of [17-21] were used for this analysis.

Extraction of water hyacinth leaf extract: $500 \mathrm{~g}$ of grounded water hyacinth sample was poured on a mushin cloth. This was then placed inside the $500 \mathrm{ml}$ soxhlet extractor thimble. $200 \mathrm{ml}$ of ethanol was poured into a round bottom flask fixed to the apparatus and the condenser was fixed tightly at the bottom end of the extractor. This set up for the experiment was heated on a heating mantle at $78^{\circ} \mathrm{C}$. The ethanol solvent was allowed to remain in contact with the water hyacinth sample for 12 hours while the remaining solvent in the oil was recovered by heating.

Experimental procedure: The corrosion study was carried out using the method described by Nwigbo et al. [22]. The mild steel coupon having dimension of $2 \mathrm{~cm} \times 3 \mathrm{~cm} \times 0.12 \mathrm{~cm}$ were polished with abrasive paper, greased to inhibit corrosion, degreased with ether of petroleum and thereafter rinsed with distilled water and dried. The mild steel coupon was suspended with the aid of a thread in $100 \mathrm{ml}$ beaker that contains $100 \mathrm{ml}$ of $0.1 \mathrm{M} \mathrm{HCl}$ with various concentrations of the inhibitor. At time interval of 2 hours, $0.1,0.5,1.0,1.5$ and $2.0 \mathrm{~g} / \mathrm{l}$ of inhibitor concentrations of $0.1 \mathrm{M} \mathrm{HCl}$ solution, and at various temperatures were studied. Each coupon after corrosion study was inserted in distilled water and dipped in methanol solution which was scrubbed to remove remaining acids, and residual concentration of inhibitors and then washed thoroughly with washing liquor, rinsed with distilled water and thereafter dried in acetone before been reweighed. The experimental plan is as shown in Tables 1 and 2 using design expert software.

Efficiency of inhibitor determination: The efficiency of corrosion inhibition was obtained using the equation below

$$
E(\%)=\frac{W_{0}-W_{1}}{W_{0}} \times 100^{3}
$$

Where, $\mathrm{W}_{0}$ is the loss in weight in uninhibited medium (blank), and $\mathrm{W}_{1}$ is the loss in weight in inhibited medium

Experimental design using RSM: The design expert software (Design - Expert 7.00) was used for the experimental runs and modeling of experimental data. Twenty (20) runs of experiment were generated with CCD (Central - Composite Design). The process variables studied were inhibitor concentration $\left(\mathrm{X}_{1}\right)$, exposure time $\left(\mathrm{X}_{2}\right)$, and temperature $\left(\mathrm{X}_{3}\right)$. These three variables were considered at five levels.

Optimization of the RSM Regression Model: Response surface methodology quadratic model generated was optimized using the global response surface equation below;

$$
Y=\beta_{0}+\sum_{i=1}^{k} \beta_{i} X_{i}+\sum_{i=1}^{k} \beta_{i i} X_{i}^{2}+\sum_{i<j} X_{i} X_{j}+e
$$

For three factor inputs of $x_{1}, x_{2}$ and $x_{3}$, the equation of the quadratic response is given as;

$$
Y=b_{o}+b_{1} X_{1}+b_{2} X_{2}+b_{3} X_{3}+b_{12} X_{1} X_{2}+b_{13} X_{1} X_{3}+b_{23} X_{2} X_{3}+b_{11} X_{1}^{2}+b_{22} X_{1}^{2}+b_{33} X_{3}^{2}
$$

$\mathrm{Y}$ is the response predicted by the Response Surface Methodology, the linear coefficient is $i$ and $j$ is the quadratic coefficients, regression coefficient is $\beta$, while parameters studied is $k$, and optimized in the experiment, and the random error is e [23].

\section{Results and Discussion}

The presence of alkaloids, saponins, terpenoids and aromatic rings in the water hyacinth chemical structure as shown in Table 3 enhanced the process of inhibiting corrosion on mild steel surface. This finding was corroborated by the report of $[8,22,24]$. Nitrogen and acetylenic alcohols molecules as contained in water hyacinth are adduced by forming a film on metal surface and thus prevent the dissolution process of the mild steel (Anodic reaction) as well as evolution of hydrogen (cathodic reaction) [25].

From Figure 1, the broad band (2655.519-2792.539 $\left.\mathrm{cm}^{-1}\right)$ exhibited aldehyde $(\mathrm{C}-\mathrm{H})$ bending. A huge band $(\mathrm{C}=\mathrm{O})$ was seen in broad band $\left(1626.748-1845.781 \mathrm{~cm}^{-1}\right)$ while alkene $\left(\mathrm{RC}=\mathrm{CH}_{2}\right)$ was revealed at broad band $923.3814 \mathrm{~cm}^{-1}$. These results were found to be consistent with literature reports of Mshandete et al. [26,27]. The study further revealed that the broad band with frequency $\left(3251.402-3519.133 \mathrm{~cm}^{-1}\right)$ exhibited RO-H (alcohol) wide branded band. Methyne C-H stretch was seen in broad band $\left(2792.539 \mathrm{~cm}^{-1}\right)$ while methylene $\mathrm{C}-\mathrm{H}$ band was shown in broad band $\left(1462.563 \mathrm{~cm}^{-1}\right)$. The preponderance of carbonyl carbon double bond groups present in the water hyacinth is an indication of its suitability as a useful corrosion inhibitor on surface of mild steel.

\section{Statistical analysis of corrosion inhibition of mild steel using water hyacinth as inhibitor}

The ANOVA results depicted in Table 4 shows that the F-value of 35.5 and $p$-value $<0.0001$ of the model gotten from mild steel corrosion inhibition using water hyacinth is significant. The experimental data obtained was well represented with the quadratic model obtained and 1.98 value of standard deviation was achieved. $\mathrm{R}^{2}$ value of 0.9695 which was considered high was achieved for the model indicating that the predicted value was close to the actual value which suggests it to be accurate [9]. The result from this study indicates that the selected factors was adequately represented by the obtained model and also depict an actual relationship among selected factors. It is seen that $96.95 \%$ of the total variation in the inhibitor efficiency of water hyacinth can be

\begin{tabular}{|c|c|c|c|c|c|}
\hline Independent Variables & $\begin{array}{c}-\boldsymbol{\alpha} \\
\mathbf{( - 2 )}\end{array}$ & $\begin{array}{c}\text { Low } \\
\text { factor } \\
\text { level (-1) }\end{array}$ & $\begin{array}{c}\text { Mid-point } \\
\text { factor level } \\
\mathbf{( 0 )}\end{array}$ & $\begin{array}{c}\text { High } \\
\text { factor } \\
\text { level (+1) }\end{array}$ & +a (+2) \\
\hline $\begin{array}{c}\text { Concentration of Inhibitor } \\
(\mathrm{g} / \mathrm{l})\end{array}$ & 0.1 & 0.5 & 1.0 & 1.5 & 2.0 \\
\hline Exposure Time, $(\mathrm{Hr})$ & 2.0 & 4.0 & 6.0 & 8.0 & 10 \\
\hline Temperature, $\left({ }^{\circ} \mathrm{C}\right)$ & 30 & 40 & 50 & 60 & 70 \\
\hline
\end{tabular}

Table 1: Central-Composite Design factor levels of independent variables.

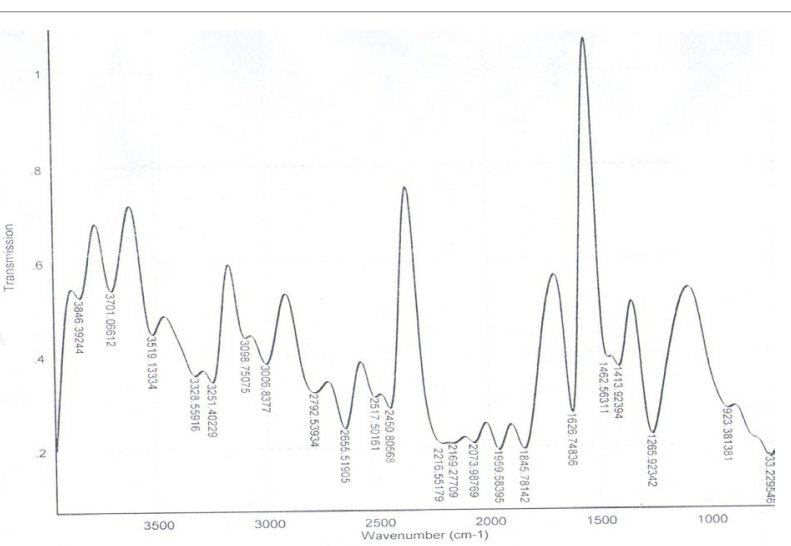

Figure 1: Water Hyacinth FTIR Spectra. 
Citation: Omoruwou F, Okewale AO, Owabor CN (2017) Statistical Analysis of Corrosion Inhibition of Water Hyacinth on Mild Steel in an Acidic Medium. J Environ Anal Toxicol 7: 481. doi: 10.4172/2161-0525.1000481

Page 3 of 5

\begin{tabular}{|c|c|c|c|}
\hline Run Order & $\begin{array}{c}\text { Inhibitor Concentration, } \\
(\mathbf{g} / \mathbf{l})\end{array}$ & $\begin{array}{c}\text { Exposure Time, } \\
\mathbf{( H r})\end{array}$ & Temperature, $\left({ }^{\circ} \mathbf{C}\right)$ \\
\hline 1 & 1 & 6 & 70 \\
\hline 2 & 1 & 6 & 50 \\
\hline 3 & 1.5 & 4 & 60 \\
\hline 4 & 1 & 6 & 50 \\
\hline 5 & 1.5 & 8 & 60 \\
\hline 6 & 0.1 & 6 & 50 \\
\hline 7 & 1 & 6 & 50 \\
\hline 8 & 1 & 10 & 50 \\
\hline 9 & 1 & 6 & 50 \\
\hline 10 & 1 & 6 & 30 \\
\hline 11 & 1.5 & 4 & 40 \\
\hline 12 & 1 & 6 & 50 \\
\hline 13 & 0.5 & 8 & 60 \\
\hline 14 & 0.5 & 4 & 60 \\
\hline 15 & 1 & 6 & 50 \\
\hline 16 & 1.5 & 8 & 40 \\
\hline 17 & 1 & 2 & 50 \\
\hline 18 & 2 & 6 & 50 \\
\hline 19 & 0.5 & 4 & 40 \\
\hline 20 & 0.5 & 8 & 40 \\
\hline
\end{tabular}

Table 2: Experimental Design Plan for CCD in Terms of Actual Variables.

\begin{tabular}{|c|c|}
\hline Chemical constituents & Percentage composition (\%) \\
\hline Alkaloid & 10.40 \\
\hline Terpenoid & 5.60 \\
\hline Phenol & Nil \\
\hline Sterols & Nil \\
\hline Flavonoid & Nil \\
\hline Cardiac glycoside & 1.80 \\
\hline Glygoside & Nil \\
\hline Tannin & Nil \\
\hline Phytosterol & 3.40 \\
\hline Saponins & 3.20 \\
\hline Anthraquinones & 2.60 \\
\hline Reducing sugar & Nil \\
\hline Phlobatannis & Nil \\
\hline
\end{tabular}

Table 3: Phytochemical Analysis of Water Hyacinth Leaf Extract.

linked to the experimental variables studied. The significance of each coefficient in the model was checked using the $\mathrm{p}$ - values which in turn were useful variables pattern [28]. An adequate precision ratio of 17.132 was obtained in this study which indicates an adequate signal. Results affirmed that there was signal adequate for the obtained model as shown by the value obtained. As depicted in Table 5, the pre $\mathrm{R}-$ squared of 0.7427 is in agreement with the Adjusted $\mathrm{R}$ - squared value of 0.9421 . The coefficient of variation the standard deviation of the mean and experimental data expressed in percentage that is $2.83 \%$, which is lesser than $10 \%$ shows that the data from the experiment is reproducible. The significant model terms at $0.05 \%$ confidence level were $\left(\mathrm{X}_{1}\right.$, and $\left.\mathrm{X}_{3}\right)$ linear terms, $\left(\mathrm{X}_{1} \mathrm{X}_{2}, \mathrm{X}_{1} \mathrm{X}_{3}\right.$, and $\left.\mathrm{X}_{2} \mathrm{X}_{3}\right)$ the interaction terms and $\left(\mathrm{X}_{1}^{2}\right.$, and $\left.\mathrm{X}_{3}^{2}\right)$ the quadratic terms. This suggests an interaction between the process variables studied which were adjudged to be the core factors that affect the corrosion rate and inhibitors efficiency of a corrosion inhibitor. The RSM model for the corrosion inhibition of mild steel using water hyacinth as an inhibitor was optimize using the desirability function of the RSM. The optimum conditions prediction from the quadratic model were inhibitor's concentratrion $(1.50 \mathrm{~g} / \mathrm{l})$, exposure time ( 8 hours), and temperature $\left(60^{\circ} \mathrm{C}\right)$ corresponding to the inhibitor's efficiency of $82.89 \%$. These were validated with an average inhibitor's efficiency of $81.5 \%$ from three replicates and this was closely approximated by the obtained optimum result predicted by the model. The experimentally obtained inhibitor's efficiency is very close to that predicted by the RSM model as seen in Tables 6 and 7 respectively.

The predicted and experimental data inhibitor's efficiency (\%) were as well investigated to determine their correlation as depicted in Figure 2. The points of the data on the plot were moderately spread close to the straight line point, an indication of a sound connection concerning the predicted values and experiment data value for the response. This further affirms that the assumptions for the analysis in the study were appropriate for the design space.

\section{Surface response plots}

3-D response surface plots of the contour were presnted in Figures 3-8. The 3-D surface plots were used to give an important evidence on the system behaviour within the experimental design on the corrosion study. The highest values of the response was credited to the considered factors in the design space as shown by the clear peak in the 3-D response plots. The corresponding plots of contour as represented by the response surfaces projection in the $x-y$ plane provided a clear and very straightforward means of ascertaining the effects of the dependent

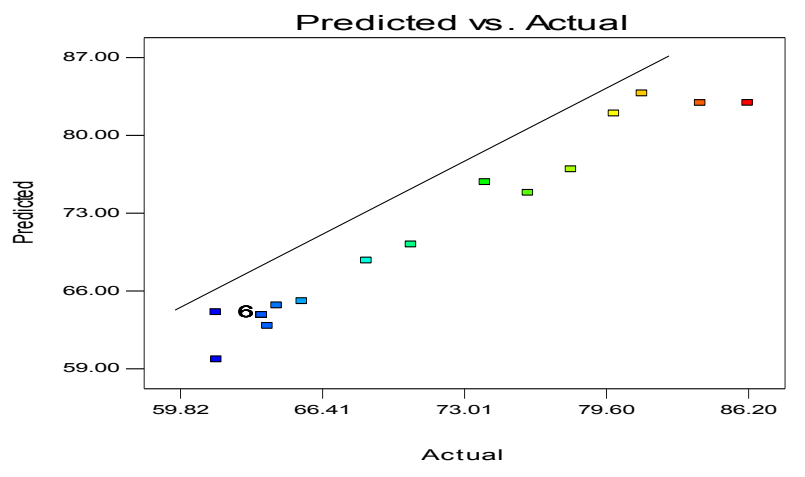

Figure 2: Predicted values versus the experimental values.

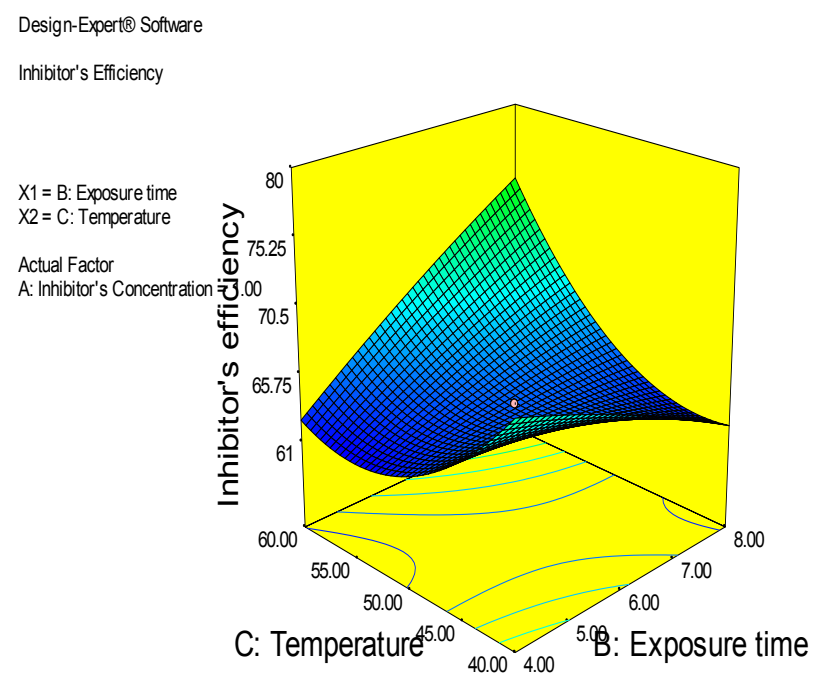

Figure 3: 3-D Response Surface Plot for the influence of exposure time, temperature, and interface with efficiency of the inhibitor. 
Citation: Omoruwou F, Okewale AO, Owabor CN (2017) Statistical Analysis of Corrosion Inhibition of Water Hyacinth on Mild Steel in an Acidic Medium. J Environ Anal Toxicol 7: 481. doi: 10.4172/2161-0525.1000481

Page 4 of 5

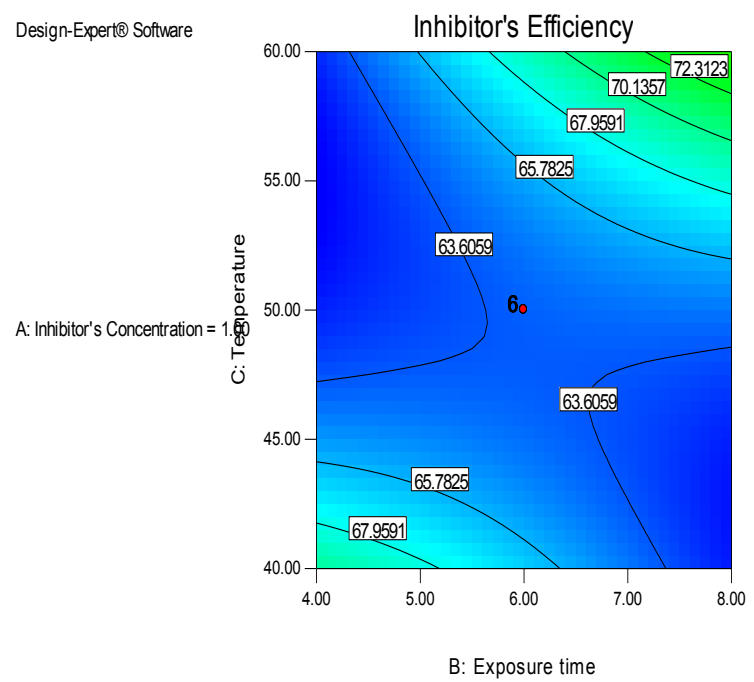

Figure 4: Plot of Contour for the influence of exposure time, temperature, and interface with efficiency of inhibitor.

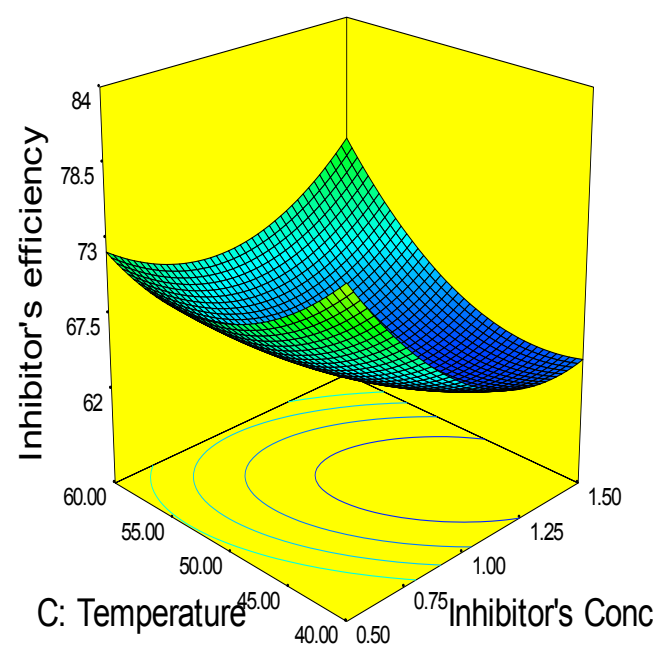

Figure 5: 3-D Response Surface Plot for the influence of inhibitor's concentration, temperature, and interface with efficiency of inhibitor.

\begin{tabular}{|c|c|c|c|c|c|}
\hline Sources & $\begin{array}{c}\text { Sum of } \\
\text { Squares }\end{array}$ & Df & $\begin{array}{c}\text { Mean } \\
\text { Square }\end{array}$ & F - Values & Prob>F, P - Value \\
\hline RSM Model & 1241.57 & 9 & 137.95 & 35.35 & $<0.0001$ Significant \\
\hline $\mathrm{X}_{1}$ & 113.55 & 1 & 113.55 & 29.10 & 0.0003 \\
\hline $\mathrm{X}_{2}$ & 18.02 & 1 & 18.02 & 4.62 & 0.0572 \\
\hline $\mathrm{X}_{3}$ & 25.25 & 1 & 25.25 & 6.47 & 0.0292 \\
\hline $\mathrm{X}_{1} \mathrm{X}_{2}$ & 69.03 & 1 & 69.03 & 17.69 & 0.0018 \\
\hline $\mathrm{X}_{1} \mathrm{X}_{3}$ & 118.89 & 1 & 118.89 & 30.46 & 0.0003 \\
\hline $\mathrm{X}_{2} \mathrm{X}_{3}$ & 193.65 & 1 & 193.65 & 49.62 & $<0.0001$ \\
\hline $\mathrm{X}_{1}{ }^{2}$ & 400.17 & 1 & 400.17 & 102.54 & $<0.0001$ \\
\hline $\mathrm{X}_{2}{ }^{2}$ & 5.55 & 1 & 5.55 & 1.42 & 0.2605 \\
\hline $\mathrm{X}_{3}{ }^{2}$ & 384.60 & 1 & 384.60 & 98.55 & $<0.0001$ \\
\hline Residual & 39.03 & 10 & 3.90 & 39.03 & - \\
\hline Lack of fit & 39.03 & 5 & 7.81 & 39.03 & - \\
\hline Pure error & 0.000 & 5 & 0.000 & 0.000 & - \\
\hline Cor Total & 1280.60 & 19 & - & - & - \\
\hline
\end{tabular}

Table 4: ANOVA of Regression Equation Results for Quadratic Model of Corrosion Inhibition Study.

\begin{tabular}{|c|c|}
\hline Parameters Deterrmined & Value \\
\hline Standard deviation & 1.98 \\
\hline Mean & 69.86 \\
\hline C.V \% & 2.83 \\
\hline R - squared & 0.9695 \\
\hline Predicted R - squared & 0.7427 \\
\hline Adjusted R - squared & 0.9421 \\
\hline
\end{tabular}

Table 5: Statistical Estimates of CCD.

\begin{tabular}{|c|c|c|c|c|}
\hline & $\begin{array}{c}\mathbf{X}_{1} \\
\text { (Inhibitor's } \\
\text { Concentration, } \\
\mathbf{g} / \mathbf{l})\end{array}$ & $\begin{array}{c}\mathbf{X}_{2} \\
\text { (Exposure Time, } \\
\mathbf{H r}\end{array}$ & $\begin{array}{c}\mathbf{X}_{3} \\
\text { (Temperature, } \\
\left.{ }^{\circ} \mathbf{C}\right)\end{array}$ & $\begin{array}{c}\text { Inhibitor's } \\
\text { Efficiency } \\
\mathbf{( \% )}\end{array}$ \\
\hline $\begin{array}{c}\text { Actual } \\
\text { Variables }\end{array}$ & 1.5 & 8.0 & 60 & 82.89 \\
\hline
\end{tabular}

Table 6: Result of the Model Optimization.

\begin{tabular}{|c|c|c|c|}
\hline $\begin{array}{c}\mathbf{Y}_{1} \text { (Inhibitor's } \\
\text { efficiency \%) }\end{array}$ & $\begin{array}{c}\mathbf{Y}_{2} \text { (Inhibitor's } \\
\text { efficiency, \%) }\end{array}$ & $\begin{array}{c}\mathbf{Y}_{3} \text { (Inhibitor's } \\
\text { efficiency, \%) }\end{array}$ & $\begin{array}{c}\mathbf{Y}_{\text {average }} \\
\text { (Inhibitor's } \\
\text { efficiency, \%) }\end{array}$ \\
\hline 80.00 & 81.81 & 82.69 & 81.50 \\
\hline
\end{tabular}

Table 7: Optimization Validation Result.

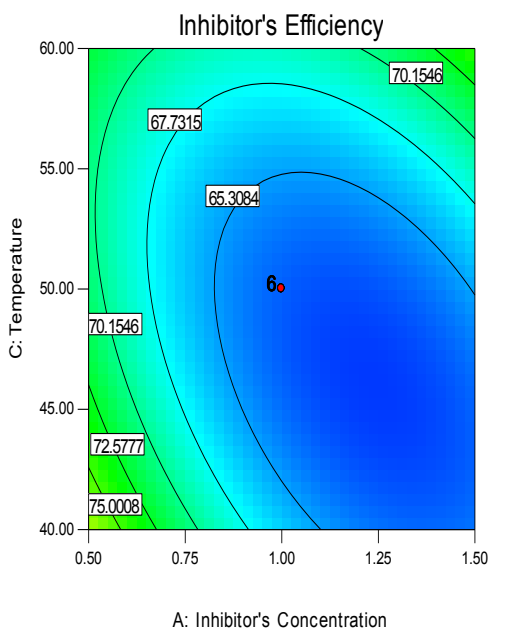

Figure 6: Plot of Contour for the influence of inhibitor's concentration, temperature, and interface with efficiency of inhibitor.

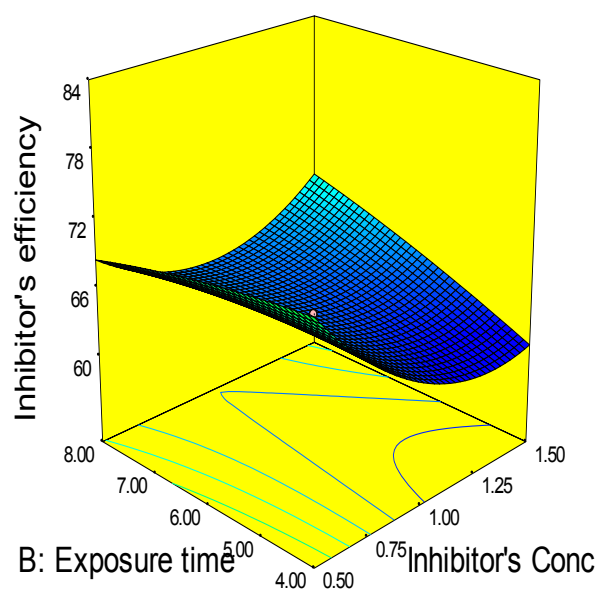

Figure 7: 3-D Response Surface Plot for the influence of inhibitor's concentration, exposure time, and interface with efficiency of inhibitor. 
Citation: Omoruwou F, Okewale AO, Owabor CN (2017) Statistical Analysis of Corrosion Inhibition of Water Hyacinth on Mild Steel in an Acidic Medium. J Environ Anal Toxicol 7: 481. doi: 10.4172/2161-0525.1000481

Page 5 of 5

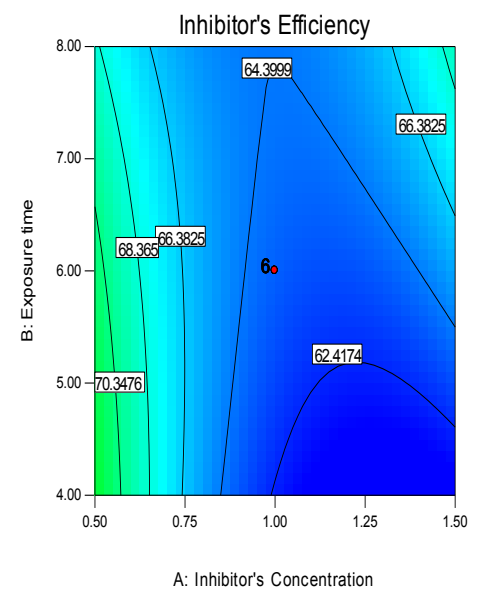

Figure 8: Plot of Contour for the influence of inhibitor's concentration, exposure time, and interface with efficiency of inhibitor.

variable independent variables. The non-circular nature of the contour plots served to indicate effect of interaction effects of the variables studied for the design space within the model.

\section{Conclusion}

The existence of saponins, alkaloids, saponins, anthraquinone, flavonoids in the phytochemical screening and the result of the FTIR showing a carbon double bond functional group affirmed that the extract of water hyacinth leaf is a good corrosion inhibitor on mild steel surface. The quadratic model developed using CCD of the response surface methodology revealed that inhibitor's concentration and temperature significantly affected the efficiency of the water hyacinth inhibitor studied.

The optimum process variables obtained from the quadratic model developed were $1.50 \mathrm{~g} / \mathrm{l}$ inhibitor's concentration, 8 hours exposure time, and temperature of $60^{\circ} \mathrm{C}$ with a predicted optimum inhibitor's efficiency value of $82.89 \%$ using the surface response methodology (CCD) modeling for the experiment design. The results gotten from the validated optimum value was in agreement with that predicted by the quadratic model.

\section{References}

1. Taylor L, Flournoy A, Hartman J (2013) Corrosion. ENGR 45 SRJC 35.

2. Dariva CG, Galio AF (2014) Corrosion inhibitors-principles, mechanisms and applications. Developments in Corrosion Protection, pp: 365-379.

3. Kavitha N, Manjula P (2014) Synergistic effect of water hyacinth Leaves $-\mathrm{Zn}^{2+}$ system in corrosion inhibition of mild steel in aqueous medium. Research Desk 3: 400-409.

4. Ghulamullar K, Kazi MD, Salim N, Wan JB, Ghulam MK, et al. (2015) Electrochemical study on the effects of Schiff Base compounds as effective corrosion inhibitor for Aluminium in acidic media. Australian Journal of Basic and Applied Sciences 9: 131-138.

5. Abiola OK, Aliyu AO, Phillips AA, Ogunsipe AO (2013) The effects of phyllanthus amarus extract on corrosion and kinetics of corrosion process of aluminium in $\mathrm{HCl}$ solution. Journal of Material Environmental Science 4: 370-373.

6. Sirajunnisa A, Fazal Mohamed MI, Subramania A (2014) Influence of aqueous extract of sida acuta leaves on corrosion inhition of aluminium in alkaline solution. Der Chemica Sinica 5: 148-156.

7. Satapathy AK, Gunasekaran G, Sahoo SC, Amit K, Rodrigues PV (2009)
Corrosion inhibition by Justica gendarussa plant extract in hydrolic acid solution. Corrosion Science 51: 2848-2856.

8. Owate IO, Nwadiuko OC, Dike II, Isu JO, Nnanna LA (2014) Inhibition of Mild Steel Corrosion by Aspilia africana in Acidic Solution. American Journal of Materials Science 4: 144-149.

9. Luo LD, Huang HY, Bi JH, Tan LL, Zhang H, et al. (2014) Optimization of malachite green by $\mathrm{KOH}$ - modified grape fruit peel activated carbon: Application of response surface methodology. The Chemical Engineering Journal 529: 751-988.

10. Fouda AS, Mohamed NH (2014) Corrosion Inhibition of Aluminum in Hydrochloric Acid Solutions using Some Chalcone Derivatives. IJIRSET 3: 9861-9875.

11. Oloruntoba DT, Popoola API, Falokun DA (2015) Investigation on water plant extract as a corrosion inhibitor for automobile engine and industry. African Corrosion Journal 1: 9-15.

12. Oloruntoba DT, Abbas JA, Olusegun SJ (2012) Water hyacinth (eichhornia crassipes) Leaves Extract as Corrosion Inhibitor for Aisi 1030 steel in sea water. West Africa Built Environment Research 4: 1131-1140.

13. Wang M, Wang J, Tan JX, Sun JF, Mou JL (2011) Optimization of ethanol fermentation from sweet sorghum juice using response surface methodology. Energy Sources 33: 1139-1146.

14. Montgomery DC (2001) Design and analysis of experiments. 5th edn. John Wiley and Sons, New York, USA.

15. Okewale AO, Igbokwe PK, Adesina OA (2015) Optimization of the adsorptive dehydration of ethanol -water system. Chemical and Process Engineering Research 39: 27-37.

16. Baş D, Boyacı H (2007) Modeling and optimization 1: Usability of response surface methodology. Journal of Food Engineering 78: 836-845.

17. Okwu DE, Josiah C (2001) Evaluation of the Chemical Composition of indigenous species and flavouring agents. Global Journal of Pure and Applied Science 7: 455-459.

18. Tanvir R, Nawaz R, Zaidi AA, Ruby S (1994) Phytochemical Screening of Medicinal Plants belonging to Euphoribiaceae Pak. Veterinary Journal 14: 160-162.

19. Sofowara A (1993) Medicinal Plants and Traditional Medicine in Africa, Ibadan, Nigeria. Spectrum Book.

20. Odeja O, Obi G, Ogwuche CE, Elemike EE, Oderinlo Y (2016) Phytochemica Screening, Antioxidant and Antimicrobial activities of Senna occidentalis (L.) Leaves Extract. Journal of Clinical Phytoscience 2: 13.

21. Herborne JB (1973) Phytochemical Methods. 3rd edn. London, Chapman and Hall Ltd., pp: 135-203.

22. Nwigbo SC, Okafor VN, Okewale AO (2012) Comparative Study of Elaeis Guiniensis Exudates (Palm Wine) as a Corrosion Inhibitor for Mild Steel in acidic and Basic Solutions. Research Journal of Applied Science Engineering and Technology 4: 1035-1039.

23. Ghorbani F, Younesi H, Ghasempouri SM, Zinatizadeh AA, Amini M, et al (2008) Application of response surface methodology for optimization of cadmium bio-sorption in an aqueous solution by saccharomyces serevisiae. Chemical Engineering Journal 145: 267-275.

24. Prithiba A, Leelavathi S, Rajalakshmi R (2014) Application of Natural Products as corrosion inhibitors in different steel and media. Chemical Science Review and Letters 3: 177-187.

25. Barmatov E, Geddes J, Hughes T, Nagl M (2012) Research on Corrosion Inhibitors for acid stimulation. Incorrosion.

26. Mshandete AM, Parawira W (2009) Biogas technology research in selected Sub-Saharan African countries A review. African Journal of Biotechnology 8 : 116-125.

27. Okewale AO, Omoruwou F, Ojaigho R (2016) Alternative energy production for Environmental sustainability. British Journal of Renewable Energy 1: 18-22.

28. Ebrahimpour A, Rahman RN, Ch'ng DH, Basri M, Salleh AB (2008) Modeling study by response surface methodology and artificial neural network on culture parameters optimization for thermostable lipase production from a newly isolated thermophilic Geobacillus sp. Strain ARM. BMC Biotechnology 8: 96-110. 